\title{
Gap Junction Inhibition Prevents Drug-induced Liver Toxicity and Fulminant Hepatic Failure
}

\author{
Suraj J Patel ${ }^{a, b}$, Jack M Milwid ${ }^{a, b}$, Kevin R King ${ }^{a}$, Stefan Bohra, Arvin Iracheta ${ }^{a}$, Matthew \\ $\mathbf{L i}^{\mathrm{a}}$, Antonia Vitalo ${ }^{\mathrm{a}}$, Biju Parekkadan ${ }^{\mathrm{a}}$, Rohit Jindal ${ }^{\mathrm{a}, \mathrm{c}}$, and Martin L Yarmush ${ }^{+, a, b, c}$ \\ ${ }^{a}$ Center for Engineering in Medicine and the Department of Surgery, Massachusetts General \\ Hospital, and the Shriners Burns Hospital, Boston, MA 02114, USA \\ bHarvard-MIT Division of Health Science and Technology, Harvard Medical School, \\ Massachusetts Institute of Technology, Cambridge, MA 02139, USA \\ 'Department of Biomedical Engineering, Rutgers University, Piscataway NJ 08854, USA
}

\begin{abstract}
Drug-induced liver injury (DILI) limits the development and utilization of numerous therapeutic compounds, and consequently presents major challenges to the pharmaceutical industry and clinical medicine ${ }^{1,2}$. Acetaminophen (APAP) containing compounds are among the most frequently prescribed drugs, and also the most common cause of $\mathrm{DILI}^{3}$. Here we describe a pharmacological strategy that targets gap junction communication to prevent amplification of fulminant hepatic failure and APAP-induced hepatotoxicity. We report that connexin 32 (Cx32), a key hepatic gap junction protein, is an essential mediator of DILI by showing that mice deficient in Cx32 are protected against liver damage, acute inflammation, and death. We identified a small molecule inhibitor of $\mathrm{Cx} 32$ as a novel hepatoprotectant that achieves the same result in wildtype mice when coadministered with known hepatotoxic drugs. These findings demonstrate that gap junction inhibition is an effective therapy for limiting DILI, and suggest a novel pharmaceutical strategy to improve drug safety.
\end{abstract}

Drug safety is an important public health concern affecting the pharmaceutical industry, regulatory agencies, and physicians. The decision to develop, approve, and prescribe a drug requires that the therapeutic benefits of medications be continuously weighed against their potential toxicities ${ }^{1,4}$. The liver represents an important target of drug toxicity because it metabolizes exogenous compounds into reactive intermediates, which can then cause progressive hepatocyte damage, fulminant hepatic failure, and death if liver transplantation is not performed ${ }^{5}$. Due to its association with significant patient morbidity and mortality, drug-induced liver injury (DILI) is the most frequently cited reason for abandoning compounds early in development or withdrawing them from the market after approval ${ }^{1,6}$. Moreover, many clinically available drugs, most notably acetaminophen, are dose limited because of their potential to induce significant liver injury ${ }^{7}$.

\footnotetext{
${ }^{+}$Correspondence should be addressed to (ireis@ @bi.org) Massachusetts General Hospital Shriners Burns Hospital 51 Blossom Street Research Boston, MA 02114 Tel: 617-726-3474 Fax: 617-573-9471.

Author Contributions. S.J.P. initiated the project, performed the experiments, analyzed data, and wrote the manuscript. J.M.M. and K.R.K. performed the experiments, provided experimental advice, and wrote the manuscript. S.B., M.L., A.I., and A.V. performed the experiments and analyzed data. R.J. and B.P. provided conceptual and editorial support. M.L.Y. supervised the project.

Competing Interests Statement. The authors have competing interests as defined by Nature Publishing Group, or other interests that might be perceived to influence the results and/or discussion reported in this article.
} 
The pathogenesis of DILI involves a multiphase process that exhibits marked spatial heterogeneity ${ }^{2,8-10}$. The liver is functionally heterogeneous at baseline, with the majority of P450 enzyme expression and drug metabolism occurring in hepatocytes near the central veins ${ }^{11}$. In the initial phase of acute DILI, the perivenular cells are preferentially injured by reactive drug metabolites while the rest of the parenchyma remains viable ${ }^{11}$. The initial direct injury, which can be dose-dependent or idiosyncratic, subsequently progresses to involve the entire hepatic lobule through host immune mechanisms that remain poorly defined $^{12}$. Interestingly, acetaminophen (APAP), the most common cause of DILI, results in hepatocellular damage that continues to occur even after the concentration of circulating hepatotoxin has declined to unmeasurable levels, suggesting an important role for propagation of preexisting injury rather than de novo direct injury ${ }^{13}$. Targeting propagation of direct hepatocyte injury represents a generalizable strategy for limiting the severity of dose-dependent and potentially idiosyncratic DILI. However, current efforts have been limited by inadequate knowledge of the molecular details underlying DILI propagation.

Recent work by our group and others have demonstrated a link between hepatic gap junctions, molecular channels composed of connexin proteins $(\mathrm{Cx})$ that enable direct intercellular communication between coupled cells ${ }^{14}$, and the amplification of liver inflammation ${ }^{15,16}$. Based on these findings, we hypothesized that liver-specific gap junction inhibitors function as a novel class of 'hepatoprotectants' that can be coformulated with hepatotoxic drugs to prevent progression of liver injury. We first examined the dependency of chemical-induced hepatotoxicity on connexin 32 (Cx32), the predominant gap junction protein expressed in the liver. Cx32-deficient $\left(\mathrm{C} \times 32^{-/-}\right)$and wildtype $\left(\mathrm{C} \times 32^{+++}\right)$mice were treated with a single dose of thioacetamide (TAA), a classic hepatotoxin known to cause fulminant hepatic failure. After 24 hours, $\mathrm{Cx} 32^{+/+}$mice had significantly elevated serum ALT/AST levels, indicative of severe hepatocellular damage, whereas $\mathrm{C} \times 32^{-/-}$mice exhibited near normal levels of ALT/AST and significantly reduced histological evidence of parenchymal damage in the liver (Fig. 1a-c). The livers of $\mathrm{C} \times 32^{+/+}$mice displayed a classic perivenular pattern of injury that extended into the hepatic lobule, while $\mathrm{Cx} 32^{-/-}$mice exhibited only a small, localized perivenular ring of injury and necrosis that did not significantly radiate throughout the hepatic lobule (Fig. 1c). The overall inflammatory response of the liver and the associated recruitment of neutrophils were also attenuated in Cx32-/- mice (Fig. 1d, e). This decreased hepatotoxicity in $\mathrm{Cx} 32^{-/-}$mice lead to a dramatic difference in TAA-induced mortality. Treatment of $\mathrm{Cx} 32^{+/+}$mice with a lethal dose of TAA resulted in $100 \%$ mortality, compared to a $100 \%$ survival in $\mathrm{Cx} 32^{-/-}$mice (Fig. 1f). We confirmed that the protective effects of gap junction deficiency were not simply a result of defective drug metabolism by showing that serum concentrations of TAA and its toxic metabolite were the same in $\mathrm{Cx} 32^{+/+}$and $\mathrm{C} \times 32^{-/-}$mice, as was phase I cytochrome $\mathrm{P} 450$ and phase II GST activity (Supplementary Fig. 1,2). Together, these results demonstrate that $\mathrm{Cx} 32$ is an essential mediator of chemical-induced liver injury, and suggest that $\mathrm{Cx} 32$ inhibition might be a viable strategy for preventing hepatotoxic effects of drugs.

Given the unique spatial distribution of both the injury and protection observed in the livers of $\mathrm{C} \times 32^{+/+}$and $\mathrm{Cx} 32^{-/-}$mice, respectively, we hypothesized that gap junction communication might promote the propagation and amplification of an injury signal after TAA treatment. Since oxidative stress is a well-established consequence of hepatotoxin exposure ${ }^{17,18}$ and free radicals are known to propagate through gap junctions, we considered the possibility that gap junctions amplify liver injury by promoting the propagation of an oxidative stress signal throughout the parenchyma. We first demonstrated the dependence of DILI on oxidative stress (Supplementary Fig. 3), and then compared the burden of intracellular free radicals in the livers of $\mathrm{C} \times 32^{+/+}$and $\mathrm{C} \times 32^{-/-}$mice. We found that livers of TAA-treated $\mathrm{Cx} 32^{+/+}$mice exhibited intense focal regions of ROS activity, while those of $\mathrm{Cx} 32^{-/-}$mice showed comparatively little activity (Supplementary Fig. 4a). 
We next devised an in vitro co-culture system to test whether hepatotoxin-exposed cells require $\mathrm{Cx} 32$ to propagate an oxidative stress signal to surrounding unexposed neighbors (Supplementary Fig. 4b,c). Connexin-deficient HeLa cells (HeLa WT) and Cx32-expressing HeLa cells (HeLa Cx32) were stimulated with the reactive metabolite of TAA (Thioacetamide sulfoxide; TASO) in the presence or absence of free radical scavengers ${ }^{18}$, and plated onto the $\mathrm{Cx} 32$-expressing hepatocyte-derived $\mathrm{H} 35$ cells preloaded with a fluorescent ROS probe (Supplementary Fig. 4c). Using this co-culture system, we detected ROS in unexposed neighbors only when they came into contact with TASO-exposed cells expressing $\mathrm{Cx} 32$, and found that this effect is prevented by pretreating the TASO-exposed cells with free radical scavengers (Supplementary Fig. 4d). Together these results suggest that $\mathrm{Cx} 32$ gap junctions propagate hepatotoxin-induced oxidative stress between hepatocytes.

To investigate the therapeutic potential of $\mathrm{Cx} 32$ inhibition for preventing hepatotoxicity, we first screened chemical libraries for small molecule inhibitors of $\mathrm{Cx} 32$ that could be administered to wildtype mice to achieve the same hepatoprotection observed in the Cx32 deficient mice. We identified 2-aminoethoxydipenyl-borate (2APB), a compound previously shown to transiently inhibit $\mathrm{Cx} 32$ gap junctions in vitro ${ }^{19}$. We determined the specificity of 2APB for $\mathrm{Cx} 32$ gap junctions by performing a calcein-AM dye-coupling "parachute" assay using Cx32- and Cx43-expressing HeLa cells (HeLa Cx32, HeLa Cx43). Treatment with 2APB blocked the spread of calcein via Cx32 gap junctions, but had a modest effect on Cx43 gap junctions (Fig. 2a,b). We then adapted the classic "scrape and load" gap junction intercellular communication assay to explanted liver slices from $\mathrm{C} \times 32^{+/+}$and $\mathrm{C} \times 32^{-/-}$mice, and demonstrated that $2 \mathrm{APB}$ effectively blocks hepatic gap junction communication in vivo (Fig. 2c). We next examined the effect of 2APB pretreatment of TAA- and APAP-induced liver injury. APAP is the active ingredient in several common over-the-counter and prescription pain medications. When wildtype mice were pretreated with a single dose of 2APB 60 minutes prior to challenge with TAA or APAP, the hepatoprotective response was strikingly similar to that observed in $\mathrm{C} \times 32^{-/-}$mice. Compared to DMSO vehicle-treated mice, those that received $2 \mathrm{APB}$ exhibited significantly reduced serum ALT and dramatically reduced histological evidence of hepatocellular injury and necrosis (Fig. 2d-g). We confirmed that the hepatoprotective effect of $2 \mathrm{APB}$ was not a result of defective drug metabolism by showing that serum concentrations of TAA and TASO were similar in mice treated with DMSO vehicle or 2APB (Supplementary Fig. 1). These findings demonstrate that $2 \mathrm{APB}$ is an effective hepatoprotectant, and support the hypothesis that targeting the $\mathrm{Cx} 32$ gap junction pathway with small molecule inhibitors represents a viable strategy for limiting DILI.

Unfortunately, pretreatment strategies for reducing drug hepatotoxicity have limited practical utility in both drug development and the clinic. Therefore, we considered a coadministration strategy, in which efficacious but potentially hepatotoxic drugs are coformulated with hepatoprotectants such as 2APB to improve their safety profiles. To develop this strategy, we used APAP, the most common cause of death due to acute liver failure ${ }^{20}$. We coadministered known hepatotoxic drugs (APAP or TAA) with the hepatoprotectant $2 \mathrm{APB}$ to wildtype mice, and compared their responses to mice receiving APAP or TAA with the appropriate DMSO vehicle. Coadministration of 2APB with either APAP or TAA dramatically reduced serum ALT, total hepatic free radicals levels, histological evidence of hepatic necrosis and hemorrhage, liver inflammation, and neutrophil infiltration to near normal levels (Fig. 3a-d and Supplementary Fig. 5). Remarkably, coadministration of 2APB reduced APAP-induced mortality from 80 to $30 \%$, and TAA-induced mortality from 100 to $0 \%$ (Fig. 3e). Furthermore, we confirmed that this hepatoprotective effect of 2APB was not a result of its vehicle, DMSO, by changing the vehicle to ethanol (Supplementary Fig. 6). Together, these results suggest a novel strategy in 
which potential hepatotoxic drugs are coformulated with hepatoprotectants, such as Cx32 inhibitors, to improve their overall safety profile and reduce the clinical incidence of DILI.

While coformulation of hepatotoxic compounds with gap junction inhibitors is an attractive strategy for future drug development, it is not directly applicable to the treatment of patients presenting after ingestion of compounds such as APAP at hepatotoxic doses. Therefore, we examined whether $\mathrm{Cx} 32$ inhibition could rescue from hepatotoxicity after drug ingestion. Single injections of 2 APB or a DMSO vehicle were given at various times after challenge with either APAP or TAA. Mice treated with 2APB 1.5 hours after either APAP or TAA administration showed a nearly complete absence of hepatotoxicity (Fig. 3f, g). Even when administered 6 hours after hepatotoxin exposure, when hepatic necrosis is already evident and toxin metabolism is completed, 2APB rescue therapy reduced serum ALT levels and limited hepatocellular damage and necrosis (Fig. 3f, g). These findings demonstrate that hepatic gap junction inhibition with potent small compounds such as $2 \mathrm{APB}$, successfully rescues from DILI and may provide a clinically useful means to treat liver injury associated with dose dependent hepatotoxic drugs such as APAP. However, the specificity of 2APB needs further investigation, as hepatoprotection might be occurring via various mechanisms, including but not limited to gap junction inhibition.

Drug-induced hepatotoxicity is classically divided into dose-dependent and idiosyncratic liver injury. The prototypical dose-dependent hepatotoxin, APAP, is the most common cause of DILI and is responsible for approximately half of the cases of acute liver failure $^{3,20}$. In contrast, idiosyncratic DILI affects over 900 clinically available drugs, but does so at a low incidence and in an unpredictable fashion ${ }^{2}$. Consequently, there are no prototypical idiopathic hepatotoxins and no experimental animal models of idiopathic DILI with which to study its pathogenesis or develop new therapies ${ }^{21}$. The strategy described here was developed in the context of dose-dependent hepatotoxins such as APAP, because of their clinical importance as well as their experimental accessibility. Given that the strategy targets the propagation phase of DILI, the possibly exists that the findings have applicability in cases of idiosyncratic DILI. Such generalizability was previously demonstrated for Nacetylcysteine (NAC), which was originally developed as an antidote for dose-dependent APAP hepatotoxicity, but has also shown benefit in the treatment of patients with nonAPAP-induced acute liver failure ${ }^{22}$. Additionally, recent evidence suggests that dosedependent and idiosyncratic DILI may share some common modes of action and therefore potentially benefit from similar therapies ${ }^{23}$.

Applications for hepatoprotectants such as 2APB range from early drug development to clinical medicine. In the pharmaceutical industry, coformulation and coadministration has previously been used to reduce gastrointestinal ${ }^{24}$ and renal toxicity ${ }^{25}$ but it has yet to be applied to hepatotoxicity, the most common reason for abandoning efficacious compounds during preclinical and clinical trials. Coformulation of hepatoprotectants such as 2APB with potential hepatotoxins represents a promising strategy for rescuing compounds in the drug development pipeline by improving their safety profiles. In clinical medicine, the hepatoprotectant coadministration strategy might be used to allow continuation of medications such as statins, antibiotics, anti-epileptics, or anti-TB drugs when they provoke significant elevations in liver enzymes or when they must be given to patients with preexisting liver disease. Finally, the most immediate clinical application of hepatoprotectants such as 2APB is in the acute management of acetaminophen overdose. Currently, the only available therapies are NAC, supportive care, and liver transplantation. We demonstrated the that $2 \mathrm{APB}$ can prevent and even rescue mice from death due to APAP toxicity, adding to the therapeutic armamentarium for treatment of this frequently fatal condition. It remains unclear to what extent $2 \mathrm{APB}$ will be helpful in idiosyncratic DILI since there are no animals models, however early success treating non-APAP DILI with NAC 
suggests the potential for generalization from dose-dependent to idiosyncratic DILI ${ }^{22}$. These applications represent promising areas for further research.

Gap junctions represent an elegant mechanism for enabling direct communication between neighboring cells. In some organs such as the heart, gap junctions have a clearly identified physiological role ${ }^{26}$ and clinical trials of modulators are currently in progress such as a Phase II trial of a gap junction inhibitor intended to prevent life threatening arrhythmias following myocardial infarction ${ }^{27}$. In the liver however, the role of gap junctions remains poorly understood. Here we show that progression of DILI is gap junction-dependent and that $\mathrm{Cx} 32$ plays an essential role in amplifying injury, making it an ideal therapeutic target for hepatoprotection.

\section{Methods}

\section{Animals and cell lines}

C57BL/6 mice were purchased from Jackson Laboratory. $C \times 32^{-/-}$mice were a generous gift (see Acknowledgements). All animal protocols were approved by Massachusetts General Hospital Subcommittee on Research Animal Care. For survival experiments, animals were euthanized when they became moribund according to the criteria of lack of response to stimuli or lack of righting reflex. H35 hepatocyte-derived cells were maintained as previously described ${ }^{28}$. Connexin 26, 32, and 43 expressing HeLa cells were gifts (see Acknowledgements).

\section{TAA-induced hepatotoxicity}

TAA (Sigma Aldrich) solution was made fresh for each experiment in $0.9 \%$ saline at $20 \mathrm{mg} /$ $\mathrm{ml}$. TAA was dosed at 200,500 or $1000 \mathrm{mg} / \mathrm{kg}$, depending on the experiment, and injected intraperitoneally. Control mice received the appropriate volume of $0.9 \%$ saline. Animals were euthanized by ketamine/xylazine injection at 24 hours for collection of serum and liver tissue for qPCR, GSH/GST assay, MPO activity assay, and histology. For survival experiments, animals were observed every 24 hours for 30 days.

\section{APAP-induced hepatotoxicity}

APAP (Sigma Aldrich) solution was made fresh for each experiment in $0.9 \%$ saline at 20 $\mathrm{mg} / \mathrm{ml}$ and heated until dissolved. APAP was dosed at 500 or $750 \mathrm{mg} / \mathrm{kg}$, and injected intraperitoneally after 15 hours of starvation. Animals were euthanized by ketamine/xylazine injection at 16 hours for collection of serum and liver tissue for MPO activity assay and histology.

\section{2-Aminoethoxydiphenyl Borate treatment}

2APB (Sigma Aldrich) was made fresh for each experiment in DMSO (200 mg/ml) or 99\% ethanol $(100 \mathrm{mg} / \mathrm{ml})$ as a vehicle. 2 APB was dosed at $1 \mathrm{or} 20 \mathrm{mg} / \mathrm{kg}$, and was administered before (60 minutes), with, or after (1.5, 3 or 6 hours) the appropriate dose of TAA or APAP. All vehicle control mice received the same volume of DMSO $(.1 \mathrm{~mL} / \mathrm{kg})$ or ethanol $(.2 \mathrm{~mL} /$ $\mathrm{kg}$ ) used to dissolve $2 \mathrm{APB}$, mixed with the appropriate volume of the hepatotoxin (TAA or APAP) dissolved in saline.

\section{DMSO treatment}

Fresh anhydrous DMSO (Sigma Aldrich) was used for each experiment. DMSO was dosed at 0.1 or $1 \mathrm{ml} / \mathrm{kg}$, and coadministered with $200 \mathrm{mg} / \mathrm{kg}$ TAA or saline. 


\section{N-Acetylcysteine treatment}

NAC (Sigma Aldrich) was made fresh for each experiment in $0.9 \%$ saline at $20 \mathrm{mg} / \mathrm{ml}$. NAC was doses at $200 \mathrm{mg} / \mathrm{kg}$, and injected intravenously in the tail vein of mice after 15 hours of starvation.

\section{Myeloperoxidase (MPO) activity assay}

Mouse liver tissues were homogenized in MPO buffer $(0.5 \%$ hexadecyl trimethyl ammonium bromide, $10 \mathrm{mM}$ EDTA, $50 \mathrm{mM} \mathrm{Na}_{2} \mathrm{HPO}_{4}$, $\mathrm{pH}$ 5.4) using a Polytron homogenizer. Liver homogenates were then subject to three freeze-thaw cycles and cleared by centrifugation. MPO reaction was carried out using the Invitrogen EnzChek Myeloperoxidase Activity Assay Kit according to the manufacturer's protocol.

\section{Quantitative RT-PCR}

Mouse liver tissues were crushed to a powder in liquid nitrogen, and total RNA was extracted using the Invitrogen Trizol RNA extraction kit, and then purified using the RT ${ }^{2}$ qPCR-Grade RNA Isolation Kit (SA Biosciences), according to the manufacturer's protocol. Total RNA (500 ng) was converted into cDNA using the RT ${ }^{2}$ First Strand Kit (SA Biosciences). Quantitative RT-PCR was performed using the Stratagene Mx3000P QPCR System and the RT ${ }^{2}$ qPCR Master Mix Kit (SA Biosciences). Quantitative RT-PCR was performed for mRNA expression of Gapdh, TNFa, pro-IL-1 $\beta$, IL6, CCL5, Cyp1a1, Cyp1a2, Cyp2e1, Cyp2b10, and Cyp3a using primers designed by SA Biosciences. Expression of Gapdh was used to standardize the samples, and the results were expressed as a ratio relative to control.

\section{Dye-coupling Parachute Assay for Gap junction communication}

HeLa Cx32 and HeLa Cx43 cells were grown to confluence, and then double-labeled with $10 \mu \mathrm{M}$ CM-DiI, a membrane dye that does not spread via gap junctions, and $10 \mu \mathrm{M}$ calcein$\mathrm{AM}$, which is converted intracellularly into the gap junction-permeable dye calcein. The labeled cells were then trypsinized, washed, and seeded onto confluent unlabeled recipient HeLa Cx32 or Cx43 cells, respectively, at a 1:200 ratio, in the presence or absence of 2APB $(25 \mu \mathrm{M})$. The labeled cells were allowed to attach to the monolayer of unlabeled cells and form gap junctions for 4 hours at $37^{\circ} \mathrm{C}$ and then examined by fluorescence microscopy. For each $2 \mathrm{APB}$ experimental condition, the number of unlabeled recipient cells positive for calcein and negative for DiI was determined and normalized to no $2 \mathrm{APB}$ control conditions.

\section{Tissue scrape and load assay for Gap junction communication}

Mice were treated i.p. with saline or 2-APB $(20 \mathrm{mg} / \mathrm{kg})$, and 3 hours later livers were excised and freshly sliced. A 27 -gauge needle was dipped into a solution containing $0.5 \%$ Lucifer Yellow (Invitrogen) and 0.5\% 10kDa dextran-Texas Red (Invitrogen), and the needle was used to both mechanically damage a small area of each slice and apply the dyes. The liver slices were incubated with the dye solution for 5 minutes, rinsed in saline, fixed in $4 \%$ paraformaldehyde for 30 minutes, frozen in OCT compound, cyro-sectioned into $7 \mu \mathrm{m}$ sections, rinsed in saline, mounted, and imaged by fluorescence microscopy.

\section{H2DCFH-DA and dihydroethidine hydrochloride (DEH) staining}

Freshly cut frozen liver sections $(7 \mu \mathrm{m})$ were stained with $10 \mu \mathrm{M}$ H2DCFH-DA (Invitrogen) or $2 \mu \mathrm{M} \mathrm{DEH}$ (Invitrogen) for 30 minutes at $37^{\circ} \mathrm{C}$, and imaged by fluorescence microscopy as previously described ${ }^{29}$. 


\section{Fluorescence microscopy}

Fluorescence images were captured on a Zeiss 200 Axiovert microscope at a fixed exposure and gain. Images for the tissue scrape load assay were quantified using custom image analysis routines written in MATLAB ${ }^{15}$. Briefly, images were median filtered, autothresholded, and segregated to identify discreet closed regions representing the spread of Lucifer Yellow dye and dextran-Texas Red. Regional outlines were plotted as contour maps by displaying iso-intensity lines at the determined threshold level.

\section{Flow cytometry}

Cultured H35 hepatocyte-derived cells were loaded with $10 \mu \mathrm{M}$ H2DCFH-DA for 30 minutes at $37^{\circ} \mathrm{C}$. This cell-permeable compound is converted into a non-fluorescent product (H2DCF), and oxidized by free radicals to the highly fluorescent dichlorofluoresceine (DCF). Cells were washed in PBS three times, and then treated with saline, TAA $(25 \mu \mathrm{M})$, TASO $(5 \mu \mathrm{M})$, or $\mathrm{H}_{2} \mathrm{O}_{2}(100 \mu \mathrm{M})$ for 2 hours, or subject to the transplant co-culture assay. After treatment, cells were trypsinized, washed in PBS, and analyzed by flow cytometry.

\section{Transplant co-culture assay}

Connexin 32 expressing $\mathrm{HeLa}(\mathrm{HeLa} \mathrm{Cx} 32)$ and connexin 43 expressing $\mathrm{HeLa}(\mathrm{HeLa} \mathrm{Cx} 43)$ cells were stimulated with saline, TASO $(5 \mu \mathrm{M})$, or $\mathrm{H}_{2} \mathrm{O}_{2}(100 \mu \mathrm{M})$ in suspension for 2 hours, in the presence or absence of cell permeable anti-oxidant MnTMPyP (Calbiochem). Two hours after treatment, HeLa cells were washed 3 times in PBS, counted, and plated onto a sub-confluent layer of H35 cells, preloaded with H2DCFH-DA, at a cell ratio of 2:1. After 4 hours of co-culture, cells were trypsinized and H35 cells were analyzed for ROS activity, as indicated by H2DCFH-DA fluorescence, by flow cytometry.

\section{HPLC-based quantification of TAA and TASO}

To quantify TAA and TASO in serum of mice, a reverse-phase HPLC assay was used, as previously described. Briefly, $7 \%$ acetonitrile, $50 \mathrm{mM}$ sodium sulfate, and $50 \mathrm{mM}$ potassium phosphate buffer was used as the mobile phase. An SPS-ODS column $(5 \mu \mathrm{m}$; Regis Technologies) was used to separate the components at $1 \mathrm{ml} / \mathrm{min}$. TAA was detected by UV absorption at $212 \mathrm{~nm}$, and TASO at $290 \mathrm{~nm}$, using a photodiode array detector. Retention times for TAA and TASO were approximately 4.1 and $3 \mathrm{~min}$, respectively. Standards were prepared by including known amounts of TAA and TASO in serum from untreated mice.

\section{Synthesis of TASO}

Thioacetamide S-Oxide (TASO) was synthesized as previously described ${ }^{30}$. Briefly, thioacetamide (TAA) was dissolved in acetone and chilled to $-5^{\circ} \mathrm{C}$. Then $30 \% \mathrm{H}_{2} \mathrm{O}_{2}$ was added rapidly, the mixture was agitated thoroughly, and stored at $4^{\circ} \mathrm{C}$ for 24 hours until the product crystallized. The product, TASO, was recovered by filtration and washed with 5 portions of cold acetone. The purity was examined by HPLC, as previously described ${ }^{30}$.

\section{Analysis of GST activity and total GSH content}

Mouse liver tissues were lysed in $100 \mathrm{mM}$ potassium phosphate, containing $2 \mathrm{mM}$ EDTA, and total protein content was determined. Enzymatic activity toward 1-chloro-2,4dinitrobenzene (CNDB) (Sigma Aldrich) was assayed in a buffer containing $100 \mathrm{mM}$ potassium phosphate, $0.1 \%$ Triton X-100, $1 \mathrm{mM}$ glutathione and $1 \mathrm{mM}$ CNDB. Formation of glutathione/CNDB conjugate was measured in a spectrophotometer at $340 \mathrm{~nm}$, as an indicator of GST activity. Total GSH content was measured using the Glutathione Assay Kit (Sigma Aldrich), as per the manufacturer's protocol. Briefly, mouse liver tissues were lysed and total protein content was determined. Samples were deproteinized with 5\% 5sulfosalicylic acid, and glutathione content of the samples was assayed using a kinetic assay 
in which catalytic amounts of glutathione cause a continuous reduction of 5,5'-dithiobis-(2nitrobenzoic) acid (DTNB) to TNB. TNB was measured colorimetrically at $412 \mathrm{~nm}$, as an indicator of total GSH content.

\section{Statistical Analysis}

Results are reported as mean plus/minus standard deviation. Statistical analysis was performed using the Student's t-test, with $\mathrm{P}<.05$ considered significant.

\section{Supplementary Material}

Refer to Web version on PubMed Central for supplementary material.

\section{Acknowledgments}

The authors thank K. Willecke (University of Bonn) and D. Paul (Harvard University) for the generous gift of Cx32-l- mice, K. Willecke (University of Bonn) for connexin expressing HeLa cells, H. Duffy (Harvard Medical School) for development of the tissue scrape and load assay for GJIC, and M. Izamis (Harvard Medical School) for HPLC assistance. S.J.P. was supported in part by a Department of Defense CDMRP Prostate Cancer Predoctoral Training Award and a Shriner Hospital for Children Postdoctoral Fellowship Award. The work was supported by grants from the US National Institutes of Health (DK059766 and P41 EB-002503) and from the Shriners Hospital for Children.

\section{Abbreviations}

$\begin{array}{ll}\text { ALT } & \text { alanine aminotransferase } \\ \text { AST } & \text { aspartate aminotransferase } \\ \text { Cx32 } & \text { connexin } 32 \\ \text { TASO } & \text { thioacetamide S-oxide } \\ \text { ROS } & \text { reactive oxygen species } \\ \text { DMSO } & \text { dimethyl sulfoxide } \\ \text { DILI } & \text { drug-induced liver injury } \\ \text { 2APB } & \text { 2-aminoethyoxydiphenyl-borate } \\ \text { TAA } & \text { thioacetamide } \\ \text { APAP } & \text { acetaminophen } \\ \text { NAC } & \text { N-Acetylcysteine }\end{array}$

\section{References}

1. Lee WM. Drug-induced hepatotoxicity. N Engl J Med. 2003; 349:474-485. [PubMed: 12890847]

2. Kaplowitz N. Idiosyncratic drug hepatotoxicity. Nat Rev Drug Discov. 2005; 4:489-499. [PubMed: 15931258]

3. Hutson S. Painkiller concerns grow ahead of new guidelines. Nat Med. 16:10. [PubMed: 20057401]

4. Platt R, Madre L, Reynolds R, Tilson H. Active drug safety surveillance: a tool to improve public health. Pharmacoepidemiol Drug Saf. 2008; 17:1175-1182. [PubMed: 18823068]

5. Navarro VJ, Senior JR. Drug-related hepatotoxicity. N Engl J Med. 2006; 354:731-739. [PubMed: 16481640]

6. Wysowski DK, Swartz L. Adverse drug event surveillance and drug withdrawals in the United States, 1969-2002: the importance of reporting suspected reactions. Arch Intern Med. 2005; 165:1363-1369. [PubMed: 15983284] 
7. Lee WM. Acetaminophen toxicity: changing perceptions on a social/medical issue. Hepatology. 2007; 46:966-970. [PubMed: 17894320]

8. Liu ZX, Han D, Gunawan B, Kaplowitz N. Neutrophil depletion protects against murine acetaminophen hepatotoxicity. Hepatology. 2006; 43:1220-1230. [PubMed: 16729305]

9. Chen CJ, et al. Identification of a key pathway required for the sterile inflammatory response triggered by dying cells. Nat Med. 2007; 13:851-856. [PubMed: 17572686]

10. Imaeda $\mathrm{AB}$, et al. Acetaminophen-induced hepatotoxicity in mice is dependent on $\mathrm{Tl} 9$ and the Nalp3 inflammasome. J Clin Invest. 2009; 119:305-314. [PubMed: 19164858]

11. Lindros KO. Zonation of cytochrome P450 expression, drug metabolism and toxicity in liver. Gen Pharmacol. 1997; 28:191-196. [PubMed: 9013193]

12. Tujios S, Fontana RJ. Mechanisms of drug-induced liver injury: from bedside to bench. Nat Rev Gastroenterol Hepatol. 8:202-211. [PubMed: 21386809]

13. Bartolone JB, Cohen SD, Khairallah EA. Immunohistochemical localization of acetaminophenbound liver proteins. Fundam Appl Toxicol. 1989; 13:859-862. [PubMed: 2695380]

14. Segretain D, Falk MM. Regulation of connexin biosynthesis, assembly, gap junction formation, and removal. Biochim Biophys Acta. 2004; 1662:3-21. [PubMed: 15033576]

15. Patel SJ, King KR, Casali M, Yarmush ML. DNA-triggered innate immune responses are propagated by gap junction communication. Proc Natl Acad Sci U S A. 2009; 106:12867-12872. [PubMed: 19617563]

16. Naiki-Ito A, et al. Gap junction dysfunction reduces acetaminophen hepatotoxicity with impact on apoptotic signaling and connexin 43 protein induction in rat. Toxicol Pathol. 38:280-286. [PubMed: 20097795]

17. Jaeschke H, et al. Mechanisms of hepatotoxicity. Toxicol Sci. 2002; 65:166-176. [PubMed: 11812920]

18. Ferret PJ, et al. Detoxification of reactive oxygen species by a nonpeptidyl mimic of superoxide dismutase cures acetaminophen-induced acute liver failure in the mouse. Hepatology. 2001; 33:1173-1180. [PubMed: 11343246]

19. Tao L, Harris AL. 2-aminoethoxydiphenyl borate directly inhibits channels composed of connexin26 and/or connexin32. Mol Pharmacol. 2007; 71:570-579. [PubMed: 17095584]

20. Chun LJ, Tong MJ, Busuttil RW, Hiatt JR. Acetaminophen hepatotoxicity and acute liver failure. J Clin Gastroenterol. 2009; 43:342-349. [PubMed: 19169150]

21. Shenton JM, Chen J, Uetrecht JP. Animal models of idiosyncratic drug reactions. Chem Biol Interact. 2004; 150:53-70. [PubMed: 15522261]

22. Lee WM, et al. Intravenous N-acetylcysteine improves transplant-free survival in early stage nonacetaminophen acute liver failure. Gastroenterology. 2009; 137:856-864. 864, e851. [PubMed: 19524577]

23. Roth RA, Ganey PE. Intrinsic versus idiosyncratic drug-induced hepatotoxicity--two villains or one? J Pharmacol Exp Ther. 332:692-697. [PubMed: 20019161]

24. Taha AS, et al. Famotidine for the prevention of gastric and duodenal ulcers caused by nonsteroidal antiinflammatory drugs. N Engl J Med. 1996; 334:1435-1439. [PubMed: 8618582]

25. Birnbaum J, Kahan FM, Kropp H, MacDonald JS. Carbapenems, a new class of beta-lactam antibiotics. Discovery and development of imipenem/cilastatin. Am J Med. 1985; 78:3-21.

26. Rohr S. Role of gap junctions in the propagation of the cardiac action potential. Cardiovasc Res. 2004; 62:309-322. [PubMed: 15094351]

27. Wit AL, Duffy HS. Drug development for treatment of cardiac arrhythmias: targeting the gap junctions. Am J Physiol Heart Circ Physiol. 2008; 294:H16-18. [PubMed: 17890421]

28. King KR, et al. A high-throughput microfluidic real-time gene expression living cell array. Lab Chip. 2007; 7:77-85. [PubMed: 17180208]

29. Owusu-Ansah E, Yavari A, Mandal S, Banerjee U. Distinct mitochondrial retrograde signals control the G1-S cell cycle checkpoint. Nat Genet. 2008; 40:356-361. [PubMed: 18246068]

30. Porter WR, Neal RA. Metabolism of thioacetamide and thioacetamide S-oxide by rat liver microsomes. Drug Metab Dispos. 1978; 6:379-388. [PubMed: 28917] 
a

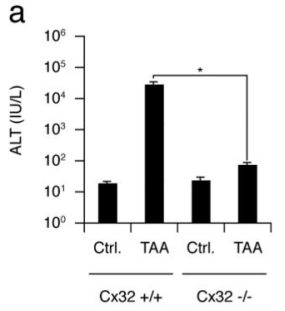

b

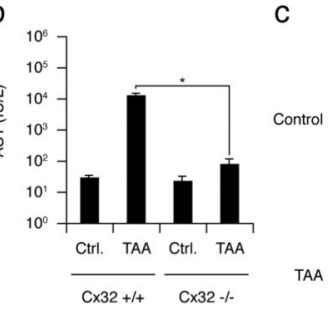

C

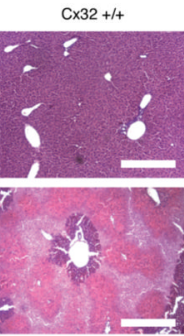

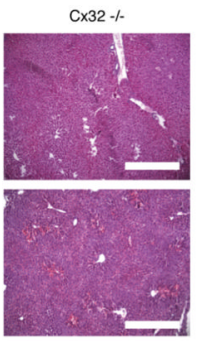

f d
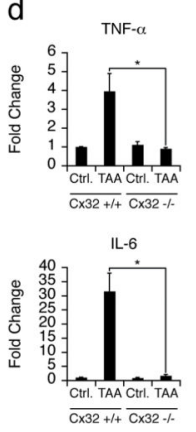
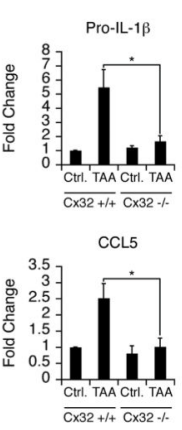

e

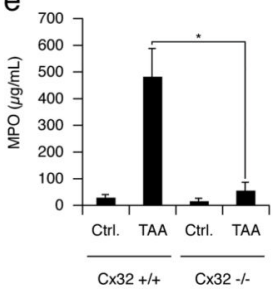

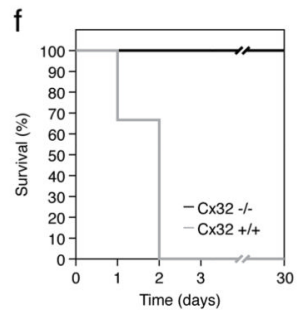

\section{Figure 1.}

Chemically-induced hepatotoxicity is dependent on connexin 32. (a,b) Significantly lower serum transaminase levels in Cx32-/- compared to Cx32+/+ mice 24 hours after treatment with a single sub-lethal dose of TAA $(200 \mathrm{mg} / \mathrm{kg}$, *P<.01). (c) Less liver hemorrhaging, necrosis, and acute inflammation in Cx32-/- mice compared to Cx32+/+ mice 24 hours after TAA treatment (H\&E staining; original magnification 10X; scale bar $=400 \mu \mathrm{m})$. (d) Decrease in total liver TNF- $\alpha$, pro-IL-1 $\beta$, IL- 6 , and CCL 5 transcripts, as measured by QPCR, in Cx32-/- mice 12 hours after TAA, compared to Cx32+/+ mice $(* \mathrm{P}<.01)$. (e) Liver tissue myeloperoxidase activity (MPO) in Cx32+/+ and Cx32-/- mice 24 hours after treatment with TAA $(* \mathrm{P}<.01)$. (f) Kaplan-Meier survival curve for $\mathrm{C} \times 32+/+$ and $\mathrm{Cx} 32-/-$ mice over 30 days after a single lethal dose of $500 \mathrm{mg} / \mathrm{kg}$ TAA (Cx32+/+ and Cx32-/-: $\mathrm{n}=12$ ). 

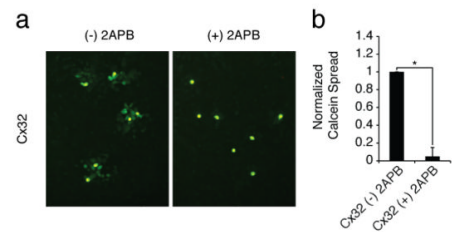

C
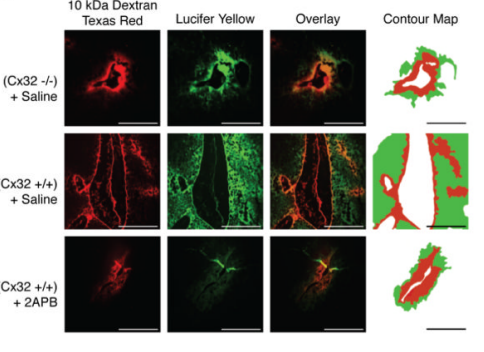

葆
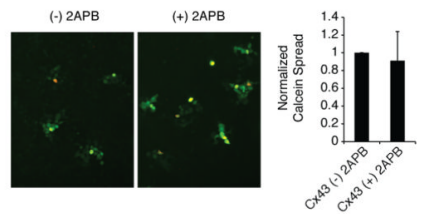

$(\mathrm{C} \times 32+/+)$
$+2 \mathrm{APB}$
+

d
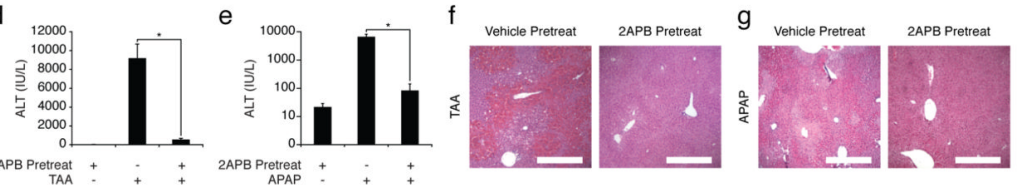

Figure 2.

Small molecule inhibitors of $\mathrm{Cx} 32$ selectively block hepatic gap junction communication and prevent drug-induced hepatotoxicity. (a, b) A dye-coupling parachute assay was used to determine the specificity of $2 \mathrm{APB}$ for $\mathrm{Cx} 32$ gap junctions compared to $\mathrm{Cx} 43$ gap junctions. $\mathrm{HeLa} \mathrm{Cx} 32$ or $\mathrm{Cx} 43$ cells were loaded with gap junction permeable calcein-AM $(10 \mu \mathrm{M})$ and impermeable CM-DiI $(10 \mu \mathrm{M})$, and seeded onto unlabeled recipient HeLa Cx32 or Cx43 cells, respectively, in the presence or absence of 2APB $(25 \mu \mathrm{M})$. (a, b) After 4 hours, the co-culture was analyzed by fluorescence microscopy $(n>5)$, and gap junction communication was assessed by calculating the average number of calcein positive cells per CM-Dil positive cell, normalized to control conditions without 2 APB treatment $\left({ }^{*} \mathrm{P}<.01\right)$. (c) A tissue version of the scrape and load test was developed to evaluate functional gap junction intercellular communication in liver tissue. $\mathrm{Cx} 32+/+$ and $\mathrm{Cx} 32-/-$ mice were treated with saline or $2 \mathrm{APB}(20 \mathrm{mg} / \mathrm{kg})$ for 3 hours. Livers were excised, cut into $2-3 \mathrm{~mm}$ slices, and a small area of each slice was mechanically damaged with the insertion of a 27 gauge needle coated with $0.5 \%$ Lucifer yellow (gap junction permeable) and $0.5 \%$ Texas red labeled dextran (gap junction impermeable). Slices were washed, fixed, cryosectioned (7 $\mu \mathrm{m})$, and analyzed by fluorescence microscopy $(n>5)$ and automated image analysis software to produce iso-intensity contour maps outlining spread of Lucifer yellow (green) and dextran-Texas red (red). Hepatic gap junction connectivity is demonstrated by the spread of gap junction permeable Lucifer yellow compared to gap junction impermeable dextran-Texas red. (d, e) Serum ALT levels and (f, g) H\&E liver histology (original magnification 10X; scale bar $=400 \mu \mathrm{m})$ from wildtype mice pretreated with $2 \mathrm{APB}(20 \mathrm{mg} /$ $\mathrm{kg}$ ) or vehicle (DMSO, $.1 \mathrm{~mL} / \mathrm{kg}$ ) 60 minutes prior to challenge with either TAA ( $200 \mathrm{mg} /$ $\mathrm{kg}$ ) or APAP $(500 \mathrm{mg} / \mathrm{kg})$, and then sacrificed 24 hours after TAA or 16 hours after APAP challenge $(* \mathrm{P}<.01)$. 


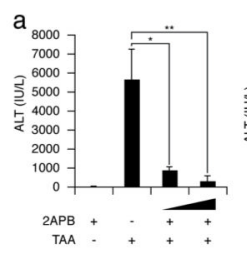

C
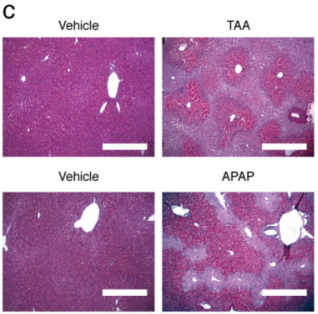

$A P A P+2 A P B$
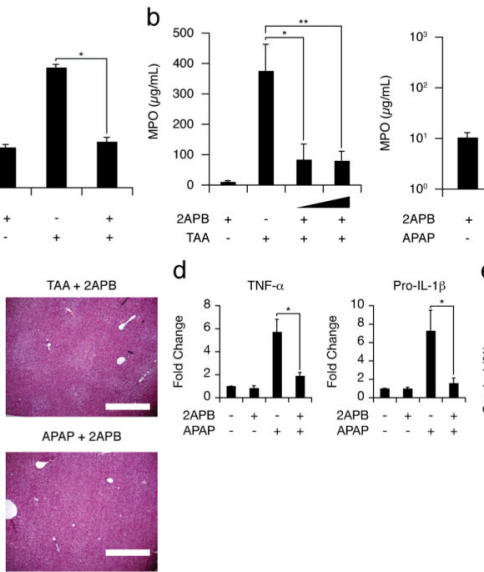

APAP
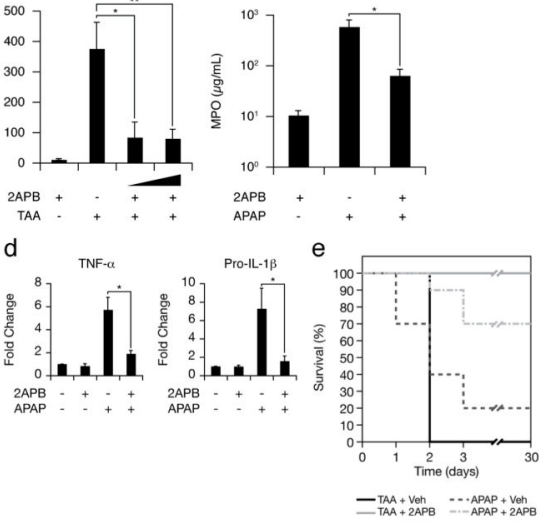

f

9 venicle $\quad 1.5 \mathrm{~h} 2 \mathrm{APB}$
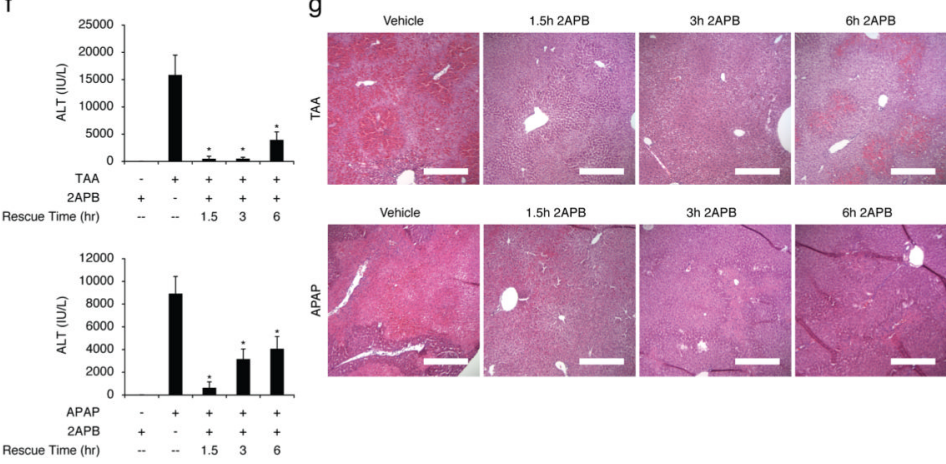

Figure 3.

Coadministration of hepatotoxic compounds with Cx32 inhibitors reduces liver injury, limits inflammation, and enhances survival. (a) Serum ALT levels, (b) liver tissue MPO activity, and (c) H\&E liver histology (original magnification 10X; scale bar $=400 \mu \mathrm{m}$ ) from wildtype mice after treatment with 2 APB alone $(20 \mathrm{mg} / \mathrm{kg})$, TAA $(200 \mathrm{mg} / \mathrm{kg})$ plus vehicle (DMSO, .1 mL/kg), TAA (200 mg/kg) plus 2APB (1 or $20 \mathrm{mg} / \mathrm{kg})$, APAP $(500 \mathrm{mg} / \mathrm{kg})$ plus vehicle (DMSO, .1 mL/kg), or APAP $(500 \mathrm{mg} / \mathrm{kg})$ plus $2 \mathrm{APB}(20 \mathrm{mg} / \mathrm{kg})$. Livers and sera were collected 24 hours after TAA challenge, or 16 hours after APAP challenge $(* \mathrm{P}<.05$, $* * \mathrm{P}<.01$ ). (d) Q-PCR for TNF- $\alpha$ and pro-IL- $1 \beta$ from whole livers of wildtype mice treated with APAP and 2APB as described above $(* \mathrm{P}<.01)$. (e) Kaplan-Meier survival curve for wildtype mice over 30 days after a single lethal dose of TAA $(500 \mathrm{mg} / \mathrm{kg})$ plus vehicle (DMSO, .1 mL/kg), TAA (500 mg/kg) plus 2APB (20 mg/kg), APAP $(750 \mathrm{mg} / \mathrm{kg})$ plus vehicle (DMSO, .1 mL/kg), or APAP (750 mg/kg) plus 2APB $(20 \mathrm{mg} / \mathrm{kg})(\mathrm{n}=10)$. (f) Serum ALT levels and (j) H\&E liver histology (original magnification 10X; scale bar $=400 \mu \mathrm{m}$ ) from wildtype mice after TAA $(200 \mathrm{mg} / \mathrm{kg})$ or APAP $(500 \mathrm{mg} / \mathrm{kg})$, with or without a rescue injection of 2APB $(20 \mathrm{mg} / \mathrm{kg}) 1.5,3$ or 6 hours after hepatotoxin challenge. Livers and sera were collected 24 hours after TAA challenge, or 16 hours after APAP challenge $\left({ }^{*} \mathrm{P}<.01\right)$. 2APB was dissolved in DMSO $(200 \mathrm{mg} / \mathrm{mL})$ for all experiments. All DMSO vehicle controls received this same amount of DMSO $(.1 \mathrm{~mL} / \mathrm{kg})$ as the $2 \mathrm{APB}$ groups, with the appropriate volume of the hepatotoxin (TAA or APAP) dissolved in saline. 